\title{
Monetary Stability and the Stability of the Open Society
}

\begin{abstract}
Historical experience shows that the welfare state is what holds democracy and the market economy together. Neither a welfare state that is too small nor one that is too large can fulfill this connective function. A "stability pact" between citizens and the state is needed: 1 . A welfare state to provide citizens security even in their old age. 2. In order to preserve appropriate incentives, the retirement system has to be a form of "saving" (forced saving) for old age. 3. In addition, most citizens also undertake voluntary saving. 4. The state provides for monetary stability. 5. The state uses its fiscal policy to promote high employment. A modern understanding of personal freedom includes the security provided by a welfare state of appropriate dimensions. It follows that in the twenty-first century, a large part of the wealth of citizens consists of net claims on the state.
\end{abstract}

\subsection{Authoritarian Tendencies, Complexity and Simplicity}

Even today, the democratically constituted "open society" is threatened by authoritarian tendencies. Many democratically minded people fear a tendency toward authoritarianism in today's world. Religious fundamentalism is an example. But the highly successful combination of a partial market economy and one-party rule in China also has observers concerned. It is worth reflecting again on the conditions of a stable, democratically constituted society.

In The Open Society and Its Enemies, Karl Popper presented what is, up to now, the most convincing fundamental approach to how a liberal-democratic social order works (Popper 1945). It is not our intention to try to outdo him on the terrain of social philosophy in our book. We understand our contribution rather as being embedded in the basic structure of the "open society" outlined by Popper. The idea

C. C. von Weizsäcker and H. M. Krämer, Saving and Investment

in the Twenty-First Century, https://doi.org/10.1007/978-3-030-75031-2_9 
of an open and therefore shapeable future and that of "piecemeal engineering" by "trial and error" form part of this basic structure.

Within this framework, what interests us are citizens' mental and behavioral dynamics. The stability of a liberal-democratic society depends on the outcome of these dynamics. We are engaging here in "political economy" in the sense that it has been practiced by economists like James Buchanan, Gordon Tullock, Amartya Sen, Alfred Müller-Armack, Mancur Olson, Peter Bernholz, Bruno Frey, Gebhard Kirchgässner and many others in modern times.

As already discussed in Chap. 2 on real capital, the success story of the West is closely linked to the development of the division of labor, which Karl Marx attributed to the "bourgeois epoch" under the heading of the "socialization of labor" (Marx and Engels 1967 [1848]; Marx 1976 [1867]). The historical process of "modernity" has led to an enormous increase in prosperity, but also in the complexity of human coexistence (cf. also Deaton 2013; Osterhammel 2010). It has always been the case that many people feel an instinctive rejection of this constantly growing social apparatus: a longing for truthfulness, "authenticity," simplicity, transparency, rootedness, and for an idealized past. In his excellent book on Romanticism in Germany, Rüdiger Safranski has revealed this common thread running from Novalis, by way of Richard Wagner, to Heidegger and Adorno (Safranski 2014). This longing - for simple truths, unshakeable beliefs, authority, for a vertical worldview with a clear "above" and "below"-is the source from which modern authoritarianism flows.

Simplicity is the opposite of complexity. Nonetheless, increased complexity, which increases prosperity in turn, comes from making use of simplifications. The abundance and variety of available goods would be inconceivable without the institution of money. Thanks to money, the transaction costs of consumerswhether those of end consumers or those of the productive consumers of intermediate products - can be reduced by orders of magnitude on the numerous goods markets they use. Money is the great simplifier. (Cf. also Simmel 1978 [1900]: The Philosophy of Money.) An important correlate is market asymmetry: On most markets for goods and services, there are many buyers, on the one hand, and a much smaller number of sellers, on the other. In keeping with the idea of the division of labor, the latter are specialized. Prices are almost always above marginal costs. Hence, in the overwhelming majority of cases, the buyer can count on the desired product being in stock. For even after a transaction has been concluded, sellers on the market in question remain hungry for more transactions, so that they have an incentive to be always ready to serve their master: the customer. By contrast, the buyer has stocked up on the product to the point that the monetary equivalent of the marginal utility that he or she derives from it is equal to its price (Gossen's Second Law): Hence, the buyer's hunger for transactions has been satiated for the time being. The simplicity of the transaction for the customer is one side of the coin. The other is the productive complexity of the market-mediated division of labor that is thus made possible (Weizsäcker 2005). 
It is worth quoting Hayek here: "It is not thanks to anyone's specific instructions that we can count on finding the things that we need to live even in an unfamiliar city or that, despite all the changes that are constantly happening in the world, we still by and large know what we will be able to procure next week or next year. We are so spoiled about this that we are more likely to complain that we have not found exactly what we expected. But actually we should be astonished that our expectations are met to such a high degree as they in fact are, even though it is nobody's obligation to ensure that we find available the things we want" (Hayek 1967).

Since there is so much talk of artificial intelligence nowadays, let us recall one of its pioneers: Herbert Simon. In 1962, Simon published an article titled "The Architecture of Complexity" in the Proceedings of the American Philosophical Society (Simon 1962). In it, he shows that complex systems have always to exhibit a property that he calls "near-decomposability." They are split up into subsystems in such a way that the interaction of the elements within a subsystem is, on average, considerably more intense than the interaction of elements from different subsystems. Insofar as the highest order subsystems are still complex systems, they are themselves split up into even smaller subsystems: and so on, until the lowest level subsystems only contain so few elements or such homogeneous elements that they lose the property of the complexity.

Simon explains the property of near-decomposability of complex systems by the advantage of evolutionary stability that it confers on them. If a system is disturbed locally at a certain point, a subsystem may be disrupted. But due to neardecomposability, this has only a minor effect on the rest of the system. The evolutionary process of "trial and error" or, in Darwinian language, "mutation and selection" can thus work. A mutation is a local disturbance. Near-decomposability ensures that it remains local. When something new develops out of the mutation, then the result is a further evolutionary step. The ability to cope with mutations or disturbances increases the threshold of tolerance for the number of mutations per unit of time and thus increases the frequency of successful evolutionary steps per unit of time. In his article, Simon shows how this abstract systems - theoretical idea can be applied to chemical, biological and social systems, as well as purely symbolic ones. Moreover, this fundamental idea was also the basis for his pioneering work in the field of artificial intelligence.

The development of the division of labor in the historical process of "modernity" is a prime example of near-decomposability. By trial and error, knowledge gets tied together into different bundles, and these bundles tend to have the property that the elements of knowledge in each bundle support one another in the task of applying it for the benefit of society. At the same time, the possessor of this knowledge relies on the fact that both the other bundles of knowledge and the agents assigned to them will work dependably, so that his or her own bundle can demonstrate its usefulness in concert with the others. Money is the unifying bond in this division of labor and of knowledge.

This near-decomposability of an economic system based on the division of labor allows economists to earn their daily bread by doing partial analyses. If, for example, the vast majority of economists with expertise in the field call for a 
uniform, global price for carbon emissions, a closer analysis of the problem reveals that their reasoning involves implicit assumptions about the near-decomposability of the global economic system. In general, all partial cost-benefit analyses and other methods of "mechanism design" are based on implicit or explicit assumptions that are tantamount to assuming the near-decomposability of the economic system.

But this near-decomposability of knowledge introduces a vast distance between the bearers of knowledge and the beneficiaries of knowledge. The world of commodities (including services) is what connects them to one another. The social relationship between bearer and beneficiary of knowledge gets "reified" in the commodity. Both the early Marx and the Marx of Capital addressed the "alienation" arising from this reification of social relationships. The subsequent Marxist tradition retained this theme. It is a key aspect of the critique of capitalism. Heidegger's critique of the "forgetfulness of being" (Seinsvergessenheit) also relates to it.

\subsection{Irenicism: The Symbiosis of Democracy and Market Economy I}

The modern welfare state in the OECD countries is a realization of the basic idea that Alfred Müller-Armack called "social irenicism" (Müller-Armack 1950): of peace between the different strata (or "classes") comprised by the population. At the same time, however, it is also a kind of peace between two principles of social and political integration: that of liberal democracy and that of the free market economy.

Carl Christian von Weizsäcker's reflections on "The Normative Co-Evolution of the Market Economy and Democracy" take up this point (Weizsäcker 2014). Here is an abbreviated version of the argument. If, pursuant to the idea of individual liberty, we want decisions on the level of the state to be normatively anchored in the preferences of citizens (the social choice approach of Arrow, Sen and others), then it has to be taken into account that these preferences are not fixed, but change rather in response to external influences. A coherent concept of social progress assumes that every path of small step-by-step improvements, in the sense of Popper's piecemeal engineering, is non-circular. Otherwise, we would not speak of progress. Now, it can be shown mathematically that such a path of progress consisting of piecemeal engineering steps is always non-circular, if preferences are "adaptive." And vice versa: If all conceivable paths of progress of this sort are non-circular, then citizens' preferences are adaptive. (The fixed preferences of the homo economicus are a special case of adaptive preferences.) Adaptive preferences can be characterized intuitively as follows: The preferences induced by the prevailing status quo valorize this status quo as compared to the preferences induced by every other status quo.

If preferences are adaptive, a majority rule democracy would thus be massively hostile to change without a market economy. The market economy gives rise to decentralized, incremental changes. When they are successful, these changes are 
justified, ex post, as progress by the associated (adaptive) changes in preferences, even though, ex ante, they would have been rejected by the majority. This allows the progress-oriented dynamics to arise that are a hallmark of the Western success story. It should be noted that the empirical results of behavioral economics consistently confirm the hypothesis of adaptive preferences. But the success story of the West is also a kind of "proof" that preferences are adaptive.

Conversely, in order to enjoy legitimacy, the decentralized decision-making system of the market economy normatively requires its embedding in a democratic political order. Since there are interpersonal influences on preferences, these preferences are not in and of themselves legitimate sources for social decisions. They only become so by being submitted to "domination-free discourse" (Habermas) in society. In the context of this discussion, citizens are free, in particular, to choose the "influencers" to which they want to be exposed. Just as in the market economy, at the level of the choice of goods, consumers can usually choose between several competitors on the producer side, so too there is a choice of influencers (the "producers" of preferences, as it were) at the level of the formation of consumer and voter preferences; i.e., there is competition among the influencers. It is only on this condition that we want to speak of preferences as legitimate sources of social decision-making processes.

\subsection{Irenicism: The Symbiosis of Democracy and Market Economy II-The Welfare State}

The normative co-evolution of the market economy and democracy does not yet tell us everything there is to know about the possibility of a de facto symbiosis between the two principles. Experience has shown that when the modern market economy is embedded in a democratic political system, it leads to the welfare state. It can thus be presumed that the welfare state is an indispensable component of a successful symbiosis of market economy and democracy.

The core of the welfare state is social security in the broad sense or what can also be called forms of social insurance. Unlike private insurance, social insurance is mandatory. The beneficiaries are typically employees. The mandatory nature of social insurance avoids the well-known problem of adverse selection: If participation in the insurance plan were voluntary, then the likelihood of participation would be greater, the greater the risk of benefits being claimed. This, however, drives up insurance premiums, and, as a result, fewer and fewer people make use of the coverage, because it becomes too expensive.

Of course, mandatory insurance with uniform or at least highly schematized insurance premiums already brings about an implicit redistribution among beneficiaries: People whose ex ante probability of using the insurance is low subsidize people whose probability of claiming coverage is high. 
In addition, like with all insurance, there is also the moral hazard problem. As compared to someone who is uninsured, people with good coverage reduce their efforts to avoid the harmful eventuality against which they are insured. People who are over-insured may even be tempted to bring about the damages in question deliberately. In such a case, we speak of "insurance fraud."

Redistribution and moral hazard reduce people's incentive to raise their standard of living by being economically productive.

These effects, which have been abstractly formulated here for every form of mandatory insurance and hence also for every form of social insurance, show that managing the welfare state is a challenging political task. Even if the great majority of voters express strong support for the basic idea of social insurance, the political system has to have the "wisdom" not to overextend such insurance to the point that the incentive to be economically productive is massively diminished. For if this happens, the state can no longer ensure the proper functioning of the social security system as a whole. The promised benefits will turn out then to have been illusorya mirage - and the productive symbiosis of democracy and market economy will be destroyed.

\subsection{The Intertemporal Aspect of Social Insurance}

The intertemporal aspect of social insurance is of particular interest in connection with the main subject of this book. As shown in Chap. 6 on public debt, a considerable part of private wealth consists of beneficiaries' claims on the system of social security in the broad sense. Claims to retirement benefits as part of the public retirement system are the most important element of this wealth. In addition, public health insurance is connected to substantial claims to future health services, which have already been paid for by beneficiaries and their employers in the form of premiums. These assets of the beneficiaries correspond to implicit public debt of the same amount.

We have discussed the example of the German public retirement plan, which is a key component of the welfare state in Germany. The original idea behind it is closely linked to the institution of the life annuity in private insurance. This basic idea has been preserved to a large extent up to today. It is — still—very common for participants in the retirement plan to conceive of it as a "quid pro quo." As an employee, I pay (and my employer pays) into the plan, so that the latter will pay me retirement benefits in my old age. Most of the beneficiaries understand that the amount of their benefits depends on how long they have paid into the plan when they were working - and also on the size of their contributions. The contributions deducted from the gross wage of the employee and the contributions, in excess of the gross wage, paid by the employer can thus be regarded as employee saving-in the same way that the premiums paid by the beneficiary of a private life annuity contract can be understood as a form of saving. Both a private life annuity contract and the public retirement plan thus create comparable incentives to earn income for retirement by working. 
In the case of the public retirement plan, however, these incentives have already been watered down some. This is, above all, due to publicly guaranteed minimum income in Germany. For people with little labor income and only irregular employment, the benefits formula can lead to retirement benefits being less than the subsistence minimum in old age. But since these benefits are deducted from the basic allowance, the earlier retirement contributions turn out to have been "for nothing." Inasmuch as one expects, or even plans, to have a low income, the mandatory contributions to the retirement plan do not work like a form of saving for the future, but simply like a "tax," which provides an additional incentive to withdraw from the labor market as much as possible. Things would be different, if, in addition to the basic subsistence allowance, people were allowed also to keep the retirement benefit claims they had acquired. We do not want, however, to enter into any detailed discussion of guaranteed minimum income here.

What is crucial is that the public retirement plan still be designed in such a way that there are not any massive incentives to withdraw from the official labor market, because legal work is burdened with high contributions (including the employers' contributions), but the benefits paid in old age bear hardly any relation anymore to the amount beneficiaries have worked.

The adoption of a populist retirement policy is a constant danger. By improving benefits, a parliamentary majority can "help out" current retirees, as well as voters who are about to reach retirement age. These electoral favors may be financed by increasing explicit public debt or by additional taxation on one or another form of value creation or by cutting public spending in other areas: for instance, on the development and maintenance of infrastructure. The full impact of the chosen method of financing increased benefits is only felt in the long term, and this impact is, moreover, distributed in a diffuse way over the whole population. Hence, the costs of such a policy may weigh less heavily in voters' current electoral choices than its immediate visible benefits.

Voters have to be kept aware of the dangers of this sort of populism.

\subsection{Subsidiarity and Stable Money: A "Stability Pact"}

As a general principle, we can say that the best way of preventing the system of social security from degenerating into a candy shop, which is no longer affordable and which is highly incompatible with economic incentives, is by following the long-established principle of subsidiarity. The state-i.e., here the system of social security in the broad sense-should only become active in providing support, and also monitoring, when self-help is insufficient. Making provision for their own future and, in particular, for their retirement years is part of individuals' helping themselves Forced saving due to employees' mandatory participation in the public retirement plan is consistent with the principle of subsidiarity - but only if the benefits formula is correctly designed, so that it does not give employees a massive incentive to withdraw from the rules of the labor market, which promote economic prosperity. 
Subsidiarity in retirement planning also entails that, beyond a minimum, people secure their own future by way of voluntary saving.

The most important function of money with stable purchasing power is that it makes it much easier for individuals to provide for their own future by saving. This principle of stable money means that there is a risk-free real interest rate that is not negative. A non-negative, risk-free real interest rate is possible under conditions of inflation, but experience shows that the real interest rate is difficult to predict under these conditions. In this case, it is difficult for savers to foresee how great their wealth will be in the distant future.

These thoughts on the importance of price stability for preserving a free democratic social order reflect the first of the constituent principles in Walter Eucken's "Principles of Economic Policy": viz., the "primacy of monetary policy" (Eucken 1952, Chap. XVI).

A "stability pact" should thus be concluded between citizens and the state, and it should contain the following components: 1 . The state provides for basic social security and a system of compulsory saving, so that employees will have a minimum level of retirement benefits adapted to their respective standard of living. 2. The state structures forced saving in the public retirement plan in such a way that for average employees it is really a matter of saving: i.e., the greater the contributions that have been paid in, the greater the retirement benefits. 3. In addition, citizens also undertake voluntary saving, so that most of them will enjoy a standard of living in their old age that goes beyond their social security retirement benefits. 4 . The state commits itself to a policy of monetary stability to make it easier-and, in many cases, even just possible - for citizens to achieve a risk-free (after tax) rate of return of at least zero on their current foregoing of consumption. 5. In its macroand labor market policies, the state is guided by the goal of high employment, so that every citizen who wants to work is also able to find work.

\subsection{A Culture of Personal Responsibility and Future-Directedness}

The welfare state, which serves as the hinge between democracy and the market economy, should neither be too extensive nor too sparse. It would be too sparse if it were only able to fulfill its most basic function poorly: viz., the function of protecting people against hardship in cases in which strictly private sector solutions cannot regularly be found. It would be too extensive if, due to effects of schematization and redistributive effects, it were severely to impair the incentive for citizens to take personal responsibility for their own future. In the first case, the majority of voters would turn against the status quo and possibly also fall for illusory authoritarian solutions. In the second case, the economic system would become overburdened, resulting in the welfare state no longer being able to keep its promises. This also could lead voters to seek refuge in authoritarian solutions. 
In order to be able to keep to the productive middle way, there needs to be a culture of personal responsibility and future-directedness as an expression of the principle of subsidiarity.

When discussing inheritance in the chapter on desired wealth, we pointed to the "multiple uses" of wealth. Individuals' efforts to protect themselves against the "risk" of great longevity are made subjectively easier to bear by the fact that they can leave the savings not required for consumption during retirement to their descendants. The heir thus becomes an implicit insurer providing a life annuity. Hence, there is far less need for a commercial insurer to provide such an annuity.

But the basic idea of the "multiple uses" of savings is more general. There are different risks in life. You can get sick and hence be inhibited from having gainful employment, and social insurance cannot cover every such risk of losing income. You can lose your job and become temporarily unemployed, or even unemployed for a longer period of time, or only be able to find a job that does not pay as well. Your family situation can change in such a way as to increase the money you need for your daily life. Someone can die before reaching old age, creating financial duress for his or her descendants. You can end up separating from your partner, which usually also leads to higher living expenses. For whatever reason, your children may suddenly need more from you-including more financially. The business of a self-employed person can start to have difficulties, which can only be overcome by an injection of equity.

Even if people emphasize just one goal of saving in surveys, it is clear to everybody that savings can also be used for other purposes if needed. There can be a variety of ways of using savings in the form of money. A particular use does not have to be decided upon in advance. The multiple uses of savings in covering all sorts of different risks means that responding to any given risk requires much less of a sacrifice of current consumption. For you would have presumably foregone this consumption to a large extent in any case, even if the particular risk had not come about at all.

But this multiplicity of uses to cover very different risks can also be the basis for a virtue of self-sufficiency: for a self-image as someone who does not have to depend on the constant help of others - in particular, of taxpayers.

It is one of the functions of the state to promote this culture of personal responsibility and individual future-directedness by making it easier for people who want to work to find work - and by making it easier for people to plan for their future by saving. It is thus the state's responsibility to provide, on the one hand, for full employment and, on the other, for monetary stability.

An important criterion for the appropriate size of the welfare state is the public sector share in national product. The best way to illustrate this idea is by using the "Laffer curve" (Uhlig and Trabandt 2011). For the state to have the highest credit rating on the capital market, it must be able to show that tax revenues are on the rising part of the Laffer curve. It can thus make clear to creditors that, in an "emergency," it will be able to increase revenues for repaying debt by raising taxes. This Laffer curve criterion sets limits to the tax-funded public sector share. 


\subsection{Inflation or Public Debt?}

If we conclude, in keeping with the foregoing analyses, that the natural rate of interest in the given tax system or in an optimal tax system is negative, then society has the choice between a negative real interest rate without public debt and price stability with positive public debt. We described price stability above as an element of the "stability pact" between state and citizens that is required for a successful symbiosis between democracy and economic dynamism in the form of the market economy.

Public debt is not a major problem, so long as the interest charged on it is not greater than the growth rate of the economy. At a negative natural rate, this condition is satisfied, so long as the state does not overdo its borrowing.

We should recall the Golden Rule of Accumulation here: In comparing different steady states, the lifetime utility of a representative citizen is maximized at the rate of interest that is equal to the growth rate. In addition to the considerations of political stability discussed in this chapter, considerations of optimal allocation also favor the "price stability with public debt" option over the "inflation without public debt" option.

But distributive considerations also speak in favor of this option. As experience shows, an inflationary environment causes greater problems for the naive saver and investor than for the astute, sophisticated investor. More affluent social strata can afford to be advised by people who have specialized in navigating through the depths and shallows of inflation. Small savers normally cannot. Rich people invest in tangible assets and shareholdings: investments that are "inflation-protected." Investment in fixed-rate financial assets is of greater relative importance for small savers. The risk aversion of small savers is greater than that of persons who possess great wealth. Eliminating the risk arising from inflation is thus far more important for small savers than for rich people (cf. Sect. 5.1.12).

\subsection{The Aspect of Freedom}

Individual freedom creates prosperity, but also heterogeneity, confusion and complexity. The longing people feel for simple solutions, clarity and security is understandable - but it can also be fertile terrain for the propagation of illusory solutions that are exploited by populist movements. The irenicism that is made possible by an appropriate dose of the welfare state is a response to the resulting political dangers for freedom. Thanks to the existence of a welfare state system that publicly ensures a certain level of private wealth, most people feel that they are on solid ground, and this enables them to accept the confusing, but also substantial benefits of personal and economic freedom. The final sentences of Karl Polanyi's The Great Transformation are fitting here: "As long as man is true to his task of creating more abundant freedom for all, he need not fear that either power or planning will turn against him and destroy the freedom he is building by their 
instrumentality. This is the meaning in a complex society; it gives us all the certainty that we need" (Polanyi 1944, p. 268).

And today this "complexity" of a liberal social order also includes the knowledge that securing peoples' futures via price stability and welfare state institutions entails the existence of significant private wealth in the form of net claims on the state.

\section{References}

Deaton, Angus. 2013. The Great Escape: Health, Wealth, and the Origins of Inequality. Princeton (NJ): Princeton University Press.

Eucken, Walter. 1952. Grundsätze der Wirtschaftspolitik. Tübingen: Mohr-Siebeck.

Hayek, Friedrich A. von. 1967. Rechtsordnung und Handelnsordnung. In Zur Einheit der Rechtsund Staatswissenschaften, ed. Erich Streißler, 195-230. Karlsruhe: C.F. Müller.

Marx, Karl. 1976 [1867]. Capital: A Critique of Political Economy, vol. 1, trans. Ben Fowkes. London: Penguin/New Left Books.

Marx, Karl and Friedrich Engels. 1967 [1848]. The Communist Manifesto, trans. Samuel Moore. London: Penguin.

Müller-Armack, Alfred. 1950. Soziale Irenik. Weltwirtschaftliches Archiv 64: 181-203.

Osterhammel, Jürgen. 2010. Die Verwandlung der Welt - Eine Geschichte des 19. Jahrhunderts. Munich: C.H. Beck-Verlag.

Polanyi, Karl. 1944. The Great Transformation. New York (NY): Farrar and Rinehart.

Popper, Karl. 1945. The Open Society and its Enemies. London: Routledge.

Safranski, Rüdiger. 2014. Romanticism: A German Affair, trans. Robert E. Goodwin. Evanston, Illinois: Northwestern University Press.

Simmel, Georg. 1978 [1900]. The Philosophy of Money, trans. Tom Bottomore and David Frisby. London: Routledge and Keegan Paul.

Simon, Herbert. 1962. The Architecture of Complexity. Proceedings of the American Philosophical Society 106 (6): 467-482.

Uhlig, Harald and Mathias Trabandt. 2011. The Laffer Curve Revisited. Journal of Monetary Economics 58 (4): 305-327.

Weizsäcker, Carl Christian von. 2005. Hayek und Keynes: Eine Synthese. Ordo 56: 95-111.

Weizsäcker, Carl Christian von. 2014. Die normative Ko-Evolution von Marktwirtschaft und Demokratie. Ordo 65: 13-43.

Open Access This chapter is licensed under the terms of the Creative Commons Attribution 4.0 International License (http://creativecommons.org/licenses/by/4.0/), which permits use, sharing, adaptation, distribution and reproduction in any medium or format, as long as you give appropriate credit to the original author(s) and the source, provide a link to the Creative Commons license and indicate if changes were made.

The images or other third party material in this chapter are included in the chapter's Creative Commons license, unless indicated otherwise in a credit line to the material. If material is not included in the chapter's Creative Commons license and your intended use is not permitted by statutory regulation or exceeds the permitted use, you will need to obtain permission directly from the copyright holder.

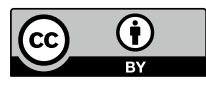

